NORTH

AMERICAN

PRIMARY CARE From the North American

RESEARC

Primary Care Research Group

Ann Fam Med 2010;8:272-273. doi:10.1370/afm.1129.

\section{MODEST BUT IMPORTANT PROGRESS IN PRIMARY CARE RESEARCH FUNDING: THE CANADIAN EXPERIENCE}

In common with the United States, Canadian primary care research has long been neglected and underfunded. This situation has persisted despite ample evidence of the key role primary care plays in producing good health outcomes, reducing disparities and controlling costs. Like our US counterparts, Canadian primary care researchers and organizations have been lobbying for at least 2 decades for enhanced funding and more focused attention to primary care research. Both the United States and Canada sit near the bottom of a number of international comparisons including use of electronic medical records, after-hours care provision, and use of non-physician clinical staff. ${ }^{1}$ For that reason, the need for reorganization of primary care is acute in both countries, along with an imperative to evaluate reforms. The Canadian situation stands apart, however, in its organization of primary care, scope and timing of system transformation, history of primary care research funding, and current funding attention to primary care research.

Close to one-half of all Canadian physicians work in primary care and the vast majority are family physicians or general practitioners, with very few specialists doing primary care. Canadian family physicians, therefore, have a larger relative presence in health care than in the United States. In Ontario, for example, there are 137,000 family physician/general practitioner visits every day but only 54,000 specialist visits; 12,000 emergency department visits; 3,000 hospital admissions; 2,000 CT or MRI scans; and 50 hip and knee replacements in a population of just over 12 million people. ${ }^{2}$ Another major difference between Canada and the United States is that Canadian primary care physicians have a single national professional organization, the College of Family Physicians of Canada (CFPC), that serves most of the multiple roles played by the family of family medicine organizations in the Unites States and it is therefore likely easier to coordinate and organize research advocacy activities.

Primary care in Canada has been undergoing system transformation for some time. In 2000, Canada's First Ministers agreed that "improvements to primary health care are crucial to the renewal of health ser- vices" and in 2004, they set a goal that $50 \%$ of Canadians should have $24 / 7$ access to multidisciplinary teams by $2011 .^{3}$ Twenty-four hour telephone advice lines have been implemented in most provinces and several provinces have made major strides in building inter-professional teams and offering primary care physicians alternate payment plans. For example, British Columbia, Saskatchewan, Ontario, and Quebec all have substantial proportions of their populations cared for in team settings. In Ontario, close to $40 \%$ of primary care physicians have voluntarily moved to blended capitation reimbursement. These substantial primary care reforms, with different natural experiments across provinces and territories, create an imperative for timely and robust research and evaluation.

Despite a history of overall neglect, primary care research did receive a transfusion of $\$ 800$ million during 2000-2006 from the Health Canada's Primary Health Care Transition Fund which supported a large number of demonstration projects, many of which included evaluation and research. ${ }^{4}$ Sadly, much of the research infrastructure vanished with the end of funding, and the external perception of the Fund is that it did not fully meet its objectives. That history has served to hamper subsequent efforts at advocacy for primary care research.

Fortunately, 2 of Canada's major national research bodies have stepped up to support primary care research. The first was the Canadian Health Services Research Foundation (CHSRF) which identified primary health care as an early priority. It later helped to establish and host the Canadian Working Group on Primary Healthcare Improvement ${ }^{5}$ and commissioned 3 papers which lay the groundwork for advocacy by describing the benefits of primary health care, international and inter-provincial gaps in care, and a structure for coordinating primary health care research. ${ }^{6}$ Persistent advocacy by the Working Group, the CFPC's Section of Researchers, and the efforts of many individuals eventually resulted in movement at the Canadian Institutes of Health Research (CIHR), Canada's equivalent of NIH. The Director, staff and advisory board of its Institute for Health Services and Policy Research have become convinced of the importance of primary health care research and for the first time in its history, CIHR has launched special primary health care competitions. To date, funding has gone to one research chair and 16 1 -year catalyst grants, with decisions still pending on 5 masters awards, 3 doctoral awards and 3 post-doctoral fellowships. CIHR also sponsored a well-attended Primary Health Care Summit held in Toronto on January 18-19, 2010. CIHR has plans to establish new primary health care funding awards for research training, career support, and a network of research centers. New fund- 
ing must be found, however, and this year will see important leadership changes so future progress cannot be taken for granted.

These modest but important successes in primary care research funding in Canada have come on the heels of several unsuccessful attempts and so they carry with them some lessons learned. These include framing family medicine more broadly to include a wide variety of primary health care practitioners and investigators, being consistent and persistent in advocacy, bringing policy-makers and national organizations on side, establishing ongoing relationships with funding decision-makers, and, most importantly, finding champions among both researchers and funders. Arguments about the impact and role of primary care in the health system were challenging to make and were not initially accepted. Graphical representations ${ }^{2,7}$ of the ecology of medical care were especially valuable and funders did eventually accept that primary care research was of importance. There is much work left to do in Canada and recent gains can easily be eroded. Nonetheless, these lessons may be instructive for advocacy in the United States and elsewhere.

Richard H. Glazier, MD, MPH Past Chair of the Section of Researchers, College of Family Pbysicians of Canada Senior Scientist, Institute for Clinical Evaluative Sciences, Toronto Associate Professor of Family and Community Medicine, University of Toronto

\section{References}

1. Schoen C, Osborn R, Doty MM, Squires D, Peugh J, Applebaum S. A survey of primary care physicians in 11 countries, 2009: perspectives on care, costs, and experiences. Health Aff (Millwood). 2009;(Nov):w1171-w1183.

2. Manuel DG, Maaten S, Thiruchelvam D, Jaakkimainen L, Upshur R. Primary care in the health care system. In: Jaakkimainen L, Upshur R, Klein-Geltink JE, et al, eds. Primary Care in Ontario: ICES Atlas. Toronto: Institute for Clinical Evaluative Sciences; 2006. http://www. ices.on.ca/file/PC_atlas_chapter1.pdf. Accessed Mar 18, 2010

3. First Minister's Meeting on the Future of Health Care 2004. http:// www.hc-sc.gc.ca/hcs-sss/delivery-prestation/fptcollab/2004-fmmrpm/index-eng.php. Accessed Mar 18, 2010.

4. Primary Health Care Transition Fund. http://www.hc-sc.gc.ca/hcssss/prim/phctf-fassp/index-eng.php. Accessed Mar 18, 2010.

5. Primary Healthcare and CHSFR. http://www.chsrf.ca/PrimaryHealthcare/PrimaryHealthcareAndCHSRF_e.php. Accessed Mar 18, 2010

6. Improving Canada's primary healthcare: benefits and opportunities. http://www.chsrf.ca/PrimaryHealthcare/ImprovingPrimaryHealthcarelnCanada_e.php. Accessed Mar 18, 2010

7. Green LA, Fryer GE Jr, Yawn BP, Lanier D, Dovey SM. The ecology of medical care revisited. N Engl J Med. 2001;344(26):2021-2025.

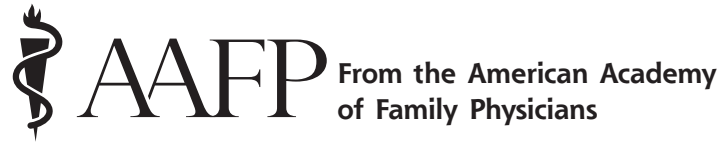

Ann Fam Med 2010;8:273-274. doi:10.1370/afm.1125.

\section{AAFP WOULD LIKE TO SEE SIGNIFICANT MODIFICATIONS IN 'MEANINGFUL USE' RULE}

The American Academy of Family Physicians (AAFP) has responded to the federal government's December 30, 2009 release of electronic health record (EHR) regulations that define the term "meaningful use" with comments detailing how the Academy would make the regulations more helpful and more palatable to family physicians.

Defining meaningful use is important because qualifying for government stimulus funds for the purchase of health information technology depends on how physician practices are meeting the regulations' criteria.

In a February 26,2010 letter to Centers for Medicare \& Medicaid Services (CMS) Acting Administrator Charlene Frizzera, AAFP Board Chair Ted Epperly, $\mathrm{MD}$, of Boise, Idaho, began by lauding CMS and the Office of the National Coordinator for Health Information Technology for the amount of energy expended to craft the regulations and the "potential health IT progress made possible with these regulations."

However, Epperly continued, "We believe that certain aspects in the details of these regulations are unworkable, excessive, or redundant and will actually impede the very goals of the legislation."

The Academy noted several areas where it saw opportunities for improvement and suggested CMS consider

- offering partial incentives for physicians using less than $100 \%$ of required criteria

- creating parity between first-year requirements for the Medicare and Medicaid programs

- changing calculations of meaningful use measures from recording of percentages to absolute counts or allowing for shorter 30-day reporting periods, and

- ensuring incentives for team-based care

The Academy also expressed concern about the regulations' definition of eligible professionals and suggested that the wording be changed to include practices participating in hospital-based organizations. "We recommend that any physician or practice that purchases certified EHR technology be eligible for incentives under Medicare and Medicaid," said Epperly. 